\title{
Compartmentalized Microfluidic Platforms: The Unrivaled Breakthrough of In Vitro Tools for Neurobiological Research
}

\author{
(-Estrela Neto, ${ }^{1,2,3 *}$ - Luís Leitão, ${ }^{1,2,4 *}$-Daniela M. Sousa, ${ }^{1,2}$ (Cecília J. Alves, ${ }^{1,2}$ @Inês S. Alencastre, ${ }^{1,2}$ \\ (DPaulo Aguiar, ${ }^{1,2}$ and ${ }^{-D}$ Meriem Lamghari ${ }^{1,2,4}$ \\ ${ }^{1}$ Instituto de Investigação e Inovação em Saúde, Universidade do Porto, 4200-135 Porto, Portugal, ${ }^{2}$ Instituto de Engenharia Biomédica, Universidade do \\ Porto, 4200-135 Porto, Portugal, ${ }^{3}$ Faculdade de Medicina da Universidade do Porto, 4200-319 Porto, Portugal, and ${ }^{4}$ Instituto de Ciências Biomédicas Abel \\ Salazar, Universidade do Porto, 4050-313 Porto, Portugal
}

Microfluidic technology has become a valuable tool to the scientific community, allowing researchers to study fine cellular mechanisms with higher variable control compared with conventional systems. It has evolved tremendously, and its applicability and flexibility made its usage grow exponentially and transversely to several research fields. This has been particularly noticeable in neuroscience research, where microfluidic platforms made it possible to address specific questions extending from axonal guidance, synapse formation, or axonal transport to the development of 3D models of the CNS to allow pharmacological testing and drug screening. Furthermore, the continuous upgrade of microfluidic platforms has allowed a deeper study of the communication occurring between different neuronal and glial cells or between neurons and other peripheral tissues, both in physiological and pathological conditions. Importantly, the evolution of microfluidic technology has always been accompanied by the development of new computational tools addressing data acquisition, analysis, and modeling.

\section{Introduction}

Neurons are highly complex cells comprising detailed electrochemical and structural features shaping their function. The cell soma extends processes that become highly branched reaching different cellular targets and tissues with distinct chemical and physical features (Millet and Gillette, 2012). Understanding how molecular and physical cues modulate the neuronal cell dynamics is a challenging task due to the difficulty in reproducing in vivo microenvironment in vitro.

Since 1970, different in vitro techniques were developed for neuronal cultures to mimic the in vivo settings. Robert Campenot was a pioneer in this era where neurons could be probed, controlled, and cultured under greater constraints (Campenot, 1977). In Campenot devices, neurons cultured in one compartment extend their axons to a second compartment, allowing the control over distinct neuronal regions (Campenot, 1977; Kimpinski et al., 1997). This breakthrough in neuronal culture allowed researchers to perform biochemical analysis and precise physicochemical treatments on isolated axonal fractions. Indeed,

Received June 1, 2016; revised Sept. 8, 2016; accepted Sept. 28, 2016.

This work was supported by Fundo Europeu de Desenvolvimento Regional funds through the COMPETE 2020, Operational Programme for Competitiveness and Internationalisation, Portugal 2020, Fundação para a Ciência e a Tecnologia/Ministério da Ciência, Tecnologia e Inovação in the framework of the project "Institute for Research and Innovation in Health Sciences" (POCI-01-0145-FEDER-007274), and PTDC/BIMMED/4041/2014. E.N. and L.L. received Ph.D. Fellowships SFRH/BD/81152/2011 and SFRH/BD/109686/2015, respectively. C.J.A. and I.S.A. received Postdoctoral Fellowships SFRH/BPD/63618/2009 and SFRH/BPD/75285/2010, respectively.

The authors declare no competing financial interests.

*E.N. and L.L. contributed equally to this study.

Correspondence should be addressed to Dr. Meriem Lamghari, Instituto de Investigação e Inovação em Saúde, Universidade do Porto, Rua Alfredo Allen 280, 4200-135 Porto, Portugal. E-mail: lamghari@ineb.up.pt.

DOI:10.1523/JNEUROSCI.1748-16.2016

Copyright $\odot 2016$ the authors $\quad 0270-6474 / 16 / 3611573-12 \$ 15.00 / 0$ the potential of nerve growth factor to enhance local neurite outgrowth was first discovered using these devices (Campenot, 1977; Kimpinski et al., 1997).

The combination of Campenot's original concept with physical sciences and engineering-evolving microtechnologies has revolutionized the way such devices were designed, allowing the production of complex, integrated, and highly controllable devices (Millet and Gillette, 2012). The first compartmentalized microfluidic devices (CMDs), derived from microelectronic technology, were mainly used for studies at microscale in the areas of chemistry and physics (Whitesides, 2006; Young and Beebe, 2010; Md Yunus, 2013). It was only in the late 1990s that these devices started to be applied to life sciences: first for bioanalysis in genetics (e.g., sizing and sorting of DNA fragments) (Chou et al., 1999) and proteomics and later by combining cell culture and microfabrication as a goal for the development of miniaturized devices (Md Yunus, 2013).

The first studies directing microfluidic technology, micropatterning, and microfabrication toward a neurobiological question appeared in 2003 by Anne M. Taylor from Noo Li Jeon's laboratory (Taylor et al., 2003). For the first time, a two-compartment microfabricated neuronal culture device was described, allowing a spatial and fluidic segregation of neuronal soma from axons (Park et al., 2006). This simple, yet pioneering, design became a key reference for many other researchers and laboratories worldwide, and the backbone for the commercialized devices available today.

The success of the microfluidic platforms in biological studies relied mainly on features, such as the low price of the fabrication materials and the easy manipulation. Through rapid prototyping and soft lithography, a commonly used technology to develop 
geometrically flexible molds, original microfluidic designs can now be created (Whitesides, 2006). Moreover, the possibility of manipulating small amounts of reagents and/or cells, its increased portability, and high reproducibility proved to be an important improvement compared with the traditional culture systems, allowing researchers to perform high throughput analysis (Young and Beebe, 2010; Gao et al., 2012; Tehranirokh et al., 2013; Xiong et al., 2014). Together, these features have allowed microfluidic technology to spread rapidly through a broad range of research areas, offering engineers and biologists flexibility over the system and experimental design, given the plethora of fabrication options. Also, biological phenomena, such as flow conditions found in capillaries in vivo (McDonald et al., 2000; Gao et al., 2012; Sackmann et al., 2014) or chemical gradients, are now easily reproduced using microfluidic technology. This novel approach is enabling new insights into neurobiological events previously unachievable through traditional cell biology techniques (Park et al., 2013b).

Ranging from the minimalistic single-cell approach to the complexity of "human-on-a-chip" format, there is now a wide variety of CMD being fabricated daily on different laboratories worldwide.

This review provides an overview of microfluidic technology impact on the neuroscience field. Current developments of microfluidic platforms in a broad range of research applications from fundamental neurobiology, such as for the study of cellular interactions between different tissues' cells, to clinics, where it is emerging as a tool for fine-tuning clinical settings and drug screening will be discussed. Moreover, the use of novel computational tools to improve the readouts of microfluidic-based platforms will also be addressed.

\section{Design and methods}

The cellular microenvironment entails highly complex signals that are determinant for cells/tissues/organs function and fate. Cells are sensitive to patterns, factors concentration, mechanical changes of the substrate (e.g., stiffness), sheer stress, chemical properties (e.g., ligand density and orientation), and spatiotemporal gradient cues (e.g., topographic features, patterning of surfaces with substances with different cellular affinities) (Folch and Toner, 2000; Meyvantsson and Beebe, 2008; Hasan et al., 2014; Sackmann et al., 2014). For the correct development of in vitro models that can mimic the in vivo microenvironment, all these factors must be taken into consideration. An accurate knowledge of the state of the art of microscale technology is of major importance so that the best tools that better suit the proposed applications can be considered (Young and Beebe, 2010; Md Yunus, 2013). Microfluidic platforms are systems that can integrate multifactorial conditions and be specifically upgraded to tailor the desired cellular microenvironment (Whitesides, 2006; Young and Beebe, 2010; Sackmann et al., 2014). Presently, the number of new devices with different designs have increased exponentially, as the methodologies used for fabrication have evolved by merging the knowledge of both biologists and engineers, ultimately leading to the cutting edge devices available nowadays.

Microfluidic devices can be assembled on different substrates by reversible or irreversible bondage (McDonald et al., 2000). The majority of the devices are fabricated by bonding the device irreversibly to glass or polymer by activating both surfaces through air or oxygen plasma. This bond will allow sustaining higher pressures within the system but hampers the surface functionalization and patterning with cells or materials and impairs sample retrieval for the following analysis. The costs of the plat- forms are substantially increased when considering microelectronic arrays as substrates. Other approaches, such as reversible magnetic bonding, were successfully explored, demonstrating superior performances compared with previously published reversible techniques to microfluidic-sized devices (Rasponi et al., 2011; Biffi et al., 2012a).

Poly(dimethylsiloxane), a silicon-based elastomeric material, has become the most suitable material to mold CMD due to its optical properties, gas permeability, biological compatibility, and low costs (Whitesides, 2006; Young and Beebe, 2010; Sackmann et al., 2014). These features led to a significant improvement in microfluidic design, including the introduction of pneumatically or hydraulically controlled valves (Unger et al., 2000; Gao et al., 2011; Brunello et al., 2013), which was only possible due to poly(dimethylsiloxane) flexibility. This allowed researchers to control the flow rate and direction within the chambers, enabling the regulation of the spatiotemporal gradients of soluble factors. By incorporating gradient generators, a range of concentrations can be generated by merging, mixing, and splitting two or more inlet flows. Different conditions can be created in parallel or in a combinatorial manner to study the dose-response and timing of biomolecules on cell fate (Zhang and van Noort, 2011; Lai et al., 2012; Wu et al., 2013; Cosson and Lutolf, 2014a; Hasan et al., 2014; Sackmann et al., 2014; Taylor et al., 2015).

Controlled gradients are used along with microfluidic technology to test the responsiveness of cells to different proteins or drugs and to support long-term culture and differentiation (Li et al., 2012; Cosson and Lutolf, 2014b; Mahadik et al., 2014). It is extensively used to appraise axonal guidance and neuron sensitivity to chemoattractive or chemorepellent cues (Kothapalli et al., 2011; Dupin et al., 2013; Sackmann et al., 2014). Flow patterns are used to increase the perfusion and, therefore, the viability and time of culture, of several in vitro systems, mainly those comprising 3D environments (Vukasinovic et al., 2009; Lai et al., 2012).

Studies aiming to explore cellular functions should address and control the substrate pattern because substrate patterning has the potential to impact cell adhesion, shape, architecture, guidance, contractility, polarity, migration, differentiation, and division (Théry, 2010; Sackmann et al., 2014). Through micropatterning, it is possible to interfere with cell behavior, manipulate, and fine-tune several biological aspects. The use of patterned surfaces mimicking the organization of in vivo tissues leads to a better differentiation and higher survival rate of cultured cells in vitro (Théry, 2010; McUsic et al., 2012). In neurobiology, patterning of different proteins has been used to improve neurons adhesion and survival and axonal pathfinding (Rhee et al., 2005; Shi et al., 2010).

Single-cell analysis of cellular contents on a microchip has also become a significant tool for revealing the biological functions of individual cells. It is important to monitor and understand single biological responses facing relevant physiological stimuli. These might be undetectable when obtaining averages of cell populations (Gao et al., 2012) by using the conventional biological techniques.

\section{Miniaturized devices for fundamental neuroscience}

The proper function of the nervous system relies on the formation of highly specific connections called synapses. Throughout neuronal development, axons have to grow and navigate through a milieu of substrates until they reach their target where synaptogenesis occurs. As such, axonal guidance is a critical process in establishing the complex neuronal architecture in which axons appropriately integrate and accurately respond to multiple sig- 
nals present in the extracellular environment, ultimately directing them toward their appropriate targets to establish normal connectivity. CMDs offer a simple, yet powerful, way to easily isolate axonal fractions and control the variables underlying axonal growth and pathfinding as well as synapse formation and function. Furthermore, as the neuronal cell connectivity is intimately linked through electrical signals, the upgrade of the microfluidic platforms by incorporating electrophysiological recordings has increased the potential of these platforms on the field.

Over the last decade, several studies took advantage of microfluidic technology to further understand the mechanisms underlying axonal behavior, such as axonal transport, local protein synthesis, and synaptogenesis (Wu et al., 2005; Cox et al., 2008; Taylor et al., 2009; Gumy et al., 2011; Lu et al., 2012; Park et al., 2014a; Kung et al., 2015). In a recent study, Lu et al. (2012) slightly modified an already described CMD, including a larger compartment to avoid neuronal death in the closed compartment, as a way to investigate the role of mitochondrial transport in axonal degeneration during Parkinson disease. With this approach, researchers were able to improve the culture settings of a fragile neuronal culture, perform live cell imaging, and analyze the movement of labeled axonal mitochondria in axons over time, arising as a promising system to better understand axonal degeneration (Lu et al., 2012), once again demonstrating the versatility of these microfluidic devices. In another study, researchers developed a platform containing axon guidance features that direct them to grow in straight and parallel lines. The unique feature of this microchip is that it has a radial array of shallow microchannels patterned on its bottom layer that not only enable spatial and fluidic isolation of neuronal soma and dendrites from axons but also physically guide them to grow in straight lines, therefore simplifying the axon length quantification process and allowing axon-specific drug screening as well as axonal regeneration studies (Park et al., 2014a).

Microfluidic devices have been of utmost importance in uncovering the fine mechanisms underlying axonal outgrowth and pathfinding. Local translation in axons, particularly in growth cones, is now widely accepted, and this was mainly due to the use of microfluidic devices in studies using isolated axonal fractions. Recently, local protein degradation is now under discussion. Taking advantage of the inherent characteristic of CMD to isolate cell soma from axons, researchers have recently demonstrated that the NGF-induced axonal outgrowth in DRG neurons uses intraaxonal ubiquitin-proteasome system activity and induces ubiquitination in growth cones. With this study, researchers suggest that axonal tuning responses may include an asymmetric local protein synthesis and degradation within the growth cone, thus allowing them to tune their response toward guidance cues (Deglincerti et al., 2015).

Regarding synapse function, an interesting example was shown by Coquinco et al. (2014), where a 3-compartment microfluidic device was used to create a model to study in vitro synaptic competition. In this model, axons originated from two separated compartments establish connectivity to a common neuronal population in a third and central compartment. By inhibiting neuronal activity on one side of the chamber, axons in the central compartment derived from the untreated neurons outgrew and formed a higher number of synapses compared with the inhibited culture. With this experimental model, they demonstrated that decreased neuronal activity within one population can influence the synapse formation and growth of axons of a competing neuronal population (Coquinco et al., 2014).

\section{Interaction of different cell populations}

CMDs have been shown to be highly advantageous to understand the complex network circuit in the CNS. More interestingly, it has been used to understand the communication between peripheral neurons and non-neuronal tissues. Communication between neurons and different cell populations is of massive interest to understand how nervous system controls tissues, both in homeostatic and pathological conditions, and the feedback loop mechanisms.

The establishment of in vitro coculture systems of central or peripheral neurons can be the starting point and the basis for stronger outcomes in developmental and regeneration studies. Although most of the in vitro approaches comprise intra-system cocultures (e.g., coculture of neuronal system cells: neurons and oligodendrocytes) (Park et al., 2012), or neurons and Schwann cells (Li et al., 2012), still, it is now often observed intersystems cocultures (e.g., nervous and skeletal system: neurons and osteoblasts) (Neto et al., 2014; Pagella et al., 2014) or nervous and muscular system: neurons and myocytes (Takeuchi et al., 2011; Southam et al., 2013) and nervous system and cancer cells (Lei et al., 2016) (Figs. 1, 2). Furthermore, it is now possible to assess single-cell interaction, in microfluidic devices, between different types of cells. Dinh et al. (2013) developed a compartmentalized neuron arraying microfluidic device, showing the feasibility of protein patterning within these devices and the possibility of arraying neurons and HEK293 cells, opening new avenues for other heterotypic cocultures to model different neurobiological interactions.

\section{Central neurons and glial cells}

Within the CNS, the major studies are focused on the myelination process. Myelin is an insulating layer that wraps the axon and enhances signal transduction by allowing electrical impulses to be transmitted efficiently along the nerve cells. Diseases associated with the impairment of the myelination or with the loss of myelin leads to a weakening of the signal transmission, ultimately resulting in debilitating diseases, such as multiple sclerosis.

The molecular basis of axon-glia signaling that triggers and regulates the formation of myelin sheets remains largely unknown. The integration of cocultures in CMD allowed the appropriated in vitro tool to unravel such interaction. Recent studies have demonstrated the benefits of using a multicompartment neuron-glia microsystem to study the process of myelination under different experimental conditions in vitro (Lee et al., 2012; Park et al., 2012; Yang et al., 2012). Yang et al. (2012) showed that an intermittent electrical stimulation protocol induces significant myelin segment formation. This achievement might be clinically relevant as it is known that functional electrical stimulation promotes regeneration following experimental spinal cord injury (Yang et al., 2012). In a different approach, Park et al. (2009) verified that, after the addition of oligodendrocytes to the axonal compartment of in vitro cultured neurons, the oligodendrocytes aligned with axonal fibers in a pattern similar to the one found in white matter tracts in vivo. Finally, in another related study, researchers developed an attractive CMD that allows different experimental coculture settings as well as up to six different pharmacological treatments to be performed in parallel in a single device (Park et al., 2012). With this platform, researchers were able to simultaneously study axon-glia communications, oligodendrocyte development and differentiation, as well the axonalspecific responses to different stimuli. Authors demonstrate that mature oligodendrocytes are required to obtain a robust myelin sheath instead of oligodendrocyte progenitor cells. Furthermore, 

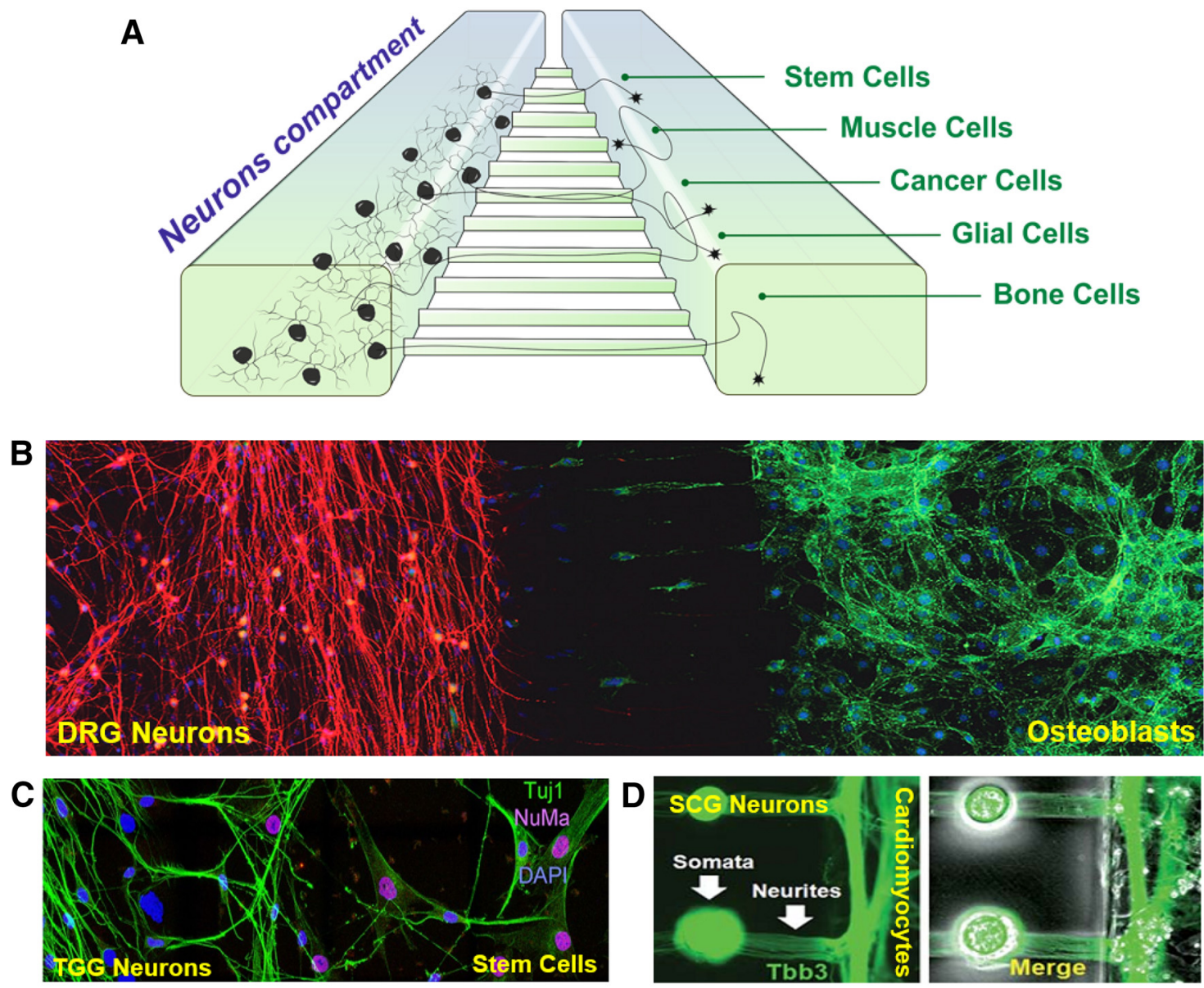

E
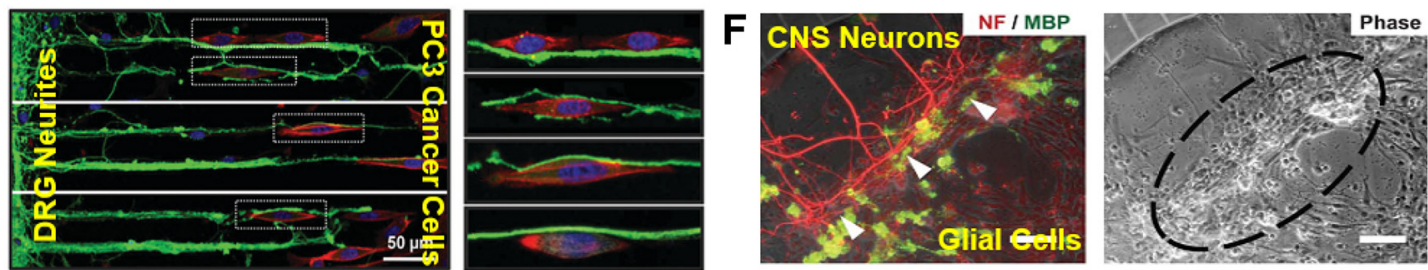

Figure 1. Coculture systems in CMDs. A, Schematic representation of CMD showing the neuronal soma cultured in a separate compartment (left) projecting axons toward the right compartment where different cell types can be cultured. B, Cocultures of DRG neurons (red) and osteoblasts (green). C, Cocultures of trigeminal ganglia neurons (TGG; left) and stem cells (right). Nuclear mitotic apparatus (NuMA) is stained with violet and $\beta$ III-tubulin (Tuj1; green). Adapted with permission from Pagella et al. (2015). D, Coculture of superior cervical ganglia neurons (SCG, left) and cardiomyocytes (right). $\boldsymbol{E}$, Coculture of DRG neurons (green) and cancer cells (red). $\boldsymbol{F}$, Coculture of CNS neurons (red) and glial cells (phase). Myelin basic protein (stained in green) and neurofilament (NF) (red). B, D, E, F, Adapted with permission from The Royal Society of Chemistry (Neto et al., 2014; Takeuchi et al., 2012; Lei et al., 2016; and Park et al., 2012 , respectively).

they also showed that the astrocytes stimulated oligodendrocyte development and are detrimental when added to a preestablished axonal layer (Park et al., 2012).

Combining CMD with stem cells, novel therapeutic approaches for treating demyelinating diseases, such as multiple sclerosis and leukodystrophies, can be explored. In a recent study, researchers cocultured neurons and oligodendrocytes derived from mouse embryonic stem cells in a modified CMD to establish a new and interesting myelin formation in vitro model (Kerman et al., 2015). With this assay, they were able to follow the myelination process over several days and obtain real-time imaging data. The large datasets of high-resolution images could then be analyzed by an automated quantification algorithm, therefore arising as a powerful tool to better understand the myelination process and to unravel new therapeutic targets to treat demyelinating disorders (Kerman et al., 2015).

\section{Peripheral neurons and muscle}

Motorneurons are specialized peripheral neurons with an unusual spatial arrangement in which its subcellular structures are exposed to very distinct extracellular microenvironments. On one side, the motorneuron soma is located centrally within the spinal cord surrounded by glial cells, whereas the axon terminal is located in the periphery in direct contact with muscle tissue, forming the neuromuscular junction, a highly specialized structure responsible for signal transmission (Hyun Sung Park et al., 2013; Southam et al., 2013). Neuromuscular signaling is a twoway crosstalk involving anterograde electrochemical signal, resulting in muscle contraction, and retrograde neurotrophic signaling to support neuronal condition. The survival and function of motorneurons and the innervated muscle tissue are highly dependent on each other (Liu et al., 2008; Park et al., 2013a; Bhatia and Ingber, 2014; Zahavi et al., 2015). Therefore, degener- 


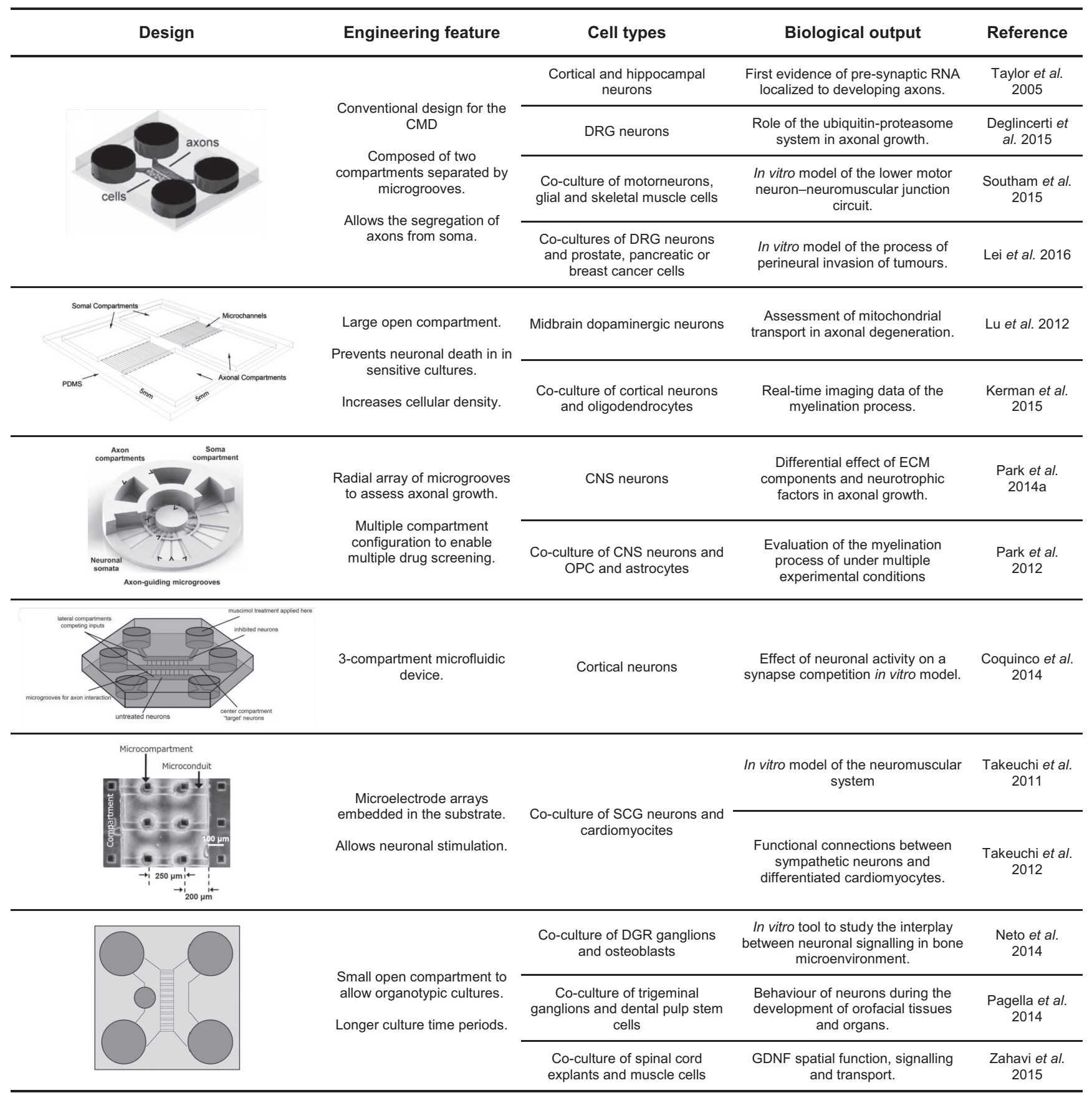

Figure 2. Examples of the different CMD designs applied in neurobiological research. ECM, Extracellular matrix; OPCs, oligodendrocyte progenitor cells; SCG, superior cervical ganglion; GDNF, glial cell-derived neurotrophic factor. Artwork adapted by permission from Macmillan Publishers (Taylor et al., 2005), Elsevier (Lu et al., 2012; Park et al. 2014a; Coquinco et al., 2014), and The Royal Society of Chemistry (Takeuchi et al., 2011; Neto et al., 2014).

ation of the neuromuscular junction is a key and early pathological feature of many motorneuron diseases and myopathies. In motorneuron disease, dysfunction of the spinal motorneuron results in muscular atrophy, even though the role of muscle-neuron interactions is yet to be fully characterized (Southam et al., 2013).

The spatial arrangement of motorneurons and the crosstalk between neurons and muscle cells arise as a technical challenge for researchers aiming to study this system accurately in vitro. CMDs are being extensively explored to unravel the mechanisms of the formation, stabilization, and degeneration of the neuromuscular junction (Croushore and Sweedler, 2013; Hyun Sung Park et al., 2013; Southam et al., 2013; Uzel et al.,
2014; Zahavi et al., 2015). Takeuchi et al. (2011) proposed the first CMD designed to mimic the neuromuscular system. In addition to the individualized compartments, separating the neurons from the myocytes, its design also included microelectrode arrays embedded in the substrate, which were used to stimulate neurons locally and record the activity of both neurons and muscle cells. Additionally, to simulate the neuromuscular junction, in vitro coculture comprising motorneurons and skeletal muscle cells has already been shown using CMD (Southam et al., 2013).

The use of CMD to investigate the mechanisms by which different cues act on neuromuscular cocultures has also been de- 
scribed. It has been shown that glial-derived neurotrophic factor acts differently whether it is applied to motorneuron soma, where it triggers cell survival, or to its axons, where it promotes growth and branching. In addition, it was possible to see, for the first time, retrograde transport of secreted glial-derived neurotrophic factor from muscle to the neuron (Zahavi et al., 2015). Furthermore, CMDs have also been successfully used to perform cocultures with autonomic neurons and cardiomyocytes (Takeuchi et al., 2011, 2012; Uzel et al., 2014; Oiwa et al., 2016). Takeuchi et al. (2012) showed that pharmacological blockage of $\beta$-adrenergic receptor, by local administration of propranolol antagonist, compromised the synaptic transmission between superior cervical ganglia neurons and cardiomyocytes.

\section{Peripheral neurons and skeletal cells}

In skeletal biology, there is an interest in the role of the peripheral nervous system in bone homeostasis. Innervation plays a key role in the development and regeneration of organs and tissues (Chenu and Marenzana, 2005; Franquinho et al., 2010; Elefteriou et al., 2014). Furthermore, it has been shown that neurons present in bone tissues actively contribute to the regulation of bone cell proliferation, migration, and differentiation (Chenu, 2004; Fukuda et al., 2013; Xu 2014). Nevertheless, the relevant molecular mechanisms of neuronbone cell interactions remain to be elucidated. We have presented a unique tool that mimics the bone microenvironment using CMD. Our team has adapted this platform for the organotypic coculture of mice DRG and osteoblasts, derived from mice bone marrow cells (Neto et al., 2014). We were able to culture osteoblasts within the microfluidic platform in 2D collagen layer and 3D arginyl-glycylaspartic acid-modified alginate hydrogel. The incorporation of the most abundant protein in the bone (collagen) and the 3D matrix provided a better substrate and environment suitable for the culture of osteoblasts. It is worth mentioning that the ability of incorporated biomaterials within these platforms is of extreme importance also from a tissue engineering perspective. We were also able to perform immunostaining for different neuronal markers and neuropeptides, such as $\beta$ III-tubulin, synapsin, and calcitonin gene-related peptide. Furthermore, to show the close interaction between sensory neurons and cocultured osteoblasts within the CMD, we have successfully performed scanning and transmission electron microscopy (Neto et al., 2014). Additionally, we developed a MATLAB-based algorithm (The MathWorks) to determine and quantify the axonal outgrowth driven by the different substrates (see Computational methods). We have presented a feasible and accurate system to study the neuronal signaling in bone microenvironment by integrating the microfluidic technology with biomaterials, 3D matrices, and optical and electronic microscopy.

Our system was a starting point to the development of new collaborations and other approaches concerning bone innervation. Dental tissue innervation was addressed by our collaborators that successfully performed organotypic cultures of dental pulp stem cells and trigeminal ganglion (Pagella et al., 2014). The CMDs allowed to maintain the tissues in culture for longer periods than were previously described in the literature. It was observed that, in culture, the tooth germs kept the ability to repeal or attract neurons as it is described for in vivo.

\section{Peripheral neurons and cancer cells}

An increasing number of studies have been suggesting that the crosstalk between neurons and cancer cells may plays a pivotal role in cancer growth and progression, there are few robust and reliable in vitro models suitable to study this interaction. To address this subject, Lei et al. (2016) took advantage of the traditional microfluidic device previously described by Taylor et al. (2005) to simulate the migration of different cancer cells associated with neurites, to mimic the process of perineural invasion of tumors in vivo (Lei et al., 2016). With this simple, yet interesting approach, they showed that neuronal processes were able to operate as a support for cancer cells guidance and migration. Furthermore, they also demonstrated that the blockade of signaling between neuronal and cancer cells impairs their migration along the neurites, suggesting a possible application of this tumor-on-chip model drug screening (Lei et al., 2016).

\section{Computational methods}

To collect the full potential of the progress made in microfluidic technology, an advance in the control, analysis, and quantification methods is also in place. It has become imperative to combine experimental readouts with computational tools to acquire, quantify, analyze, and model data. The ability of microfluidicbased platforms to spatially isolate distinct neuronal components has allowed researchers to develop computational algorithms that analyze, in an unbiased and automated manner, cellular mechanisms that otherwise would be time-consuming, tedious, and prone to human error. Computational methods focused on leveraging microfluidic-based platforms are currently being developed in complementary domains. These include the following: (1) control (Prieto et al., 2012; Frank and Tay, 2015), signal processing and data analysis, namely, specialized image processing algorithms targeting morphometric analysis of neuronal structures (Chokshi et al., 2010; Shi et al., 2011; Li et al., 2014; Neto et al., 2014; Park et al., 2014a; Kerman et al., 2015); (2) computer modeling, bridging microfluidics experimental data and theoretical models (Ebbesen and Bruus, 2012; Li et al., 2015; Nguyen et al., 2016) but also toward the optimization of microfluidic platforms using techniques, such as computational fluid dynamics (Santillo et al., 2007; Huang et al., 2010); and (3) automated control systems to manage sensors and actuators on advanced microfluidic platforms (Kothapalli et al., 2011; Biffi et al., 2012a; Moreno et al., 2015) (Fig. 3).

The newly available image processing algorithms have been particularly important in studies regarding axonal behavior, namely, in outgrowth, guidance, and degeneration. By taking advantage of the main features of the microfluidic platforms (e.g., compartmentalization and chamber transparency), these algorithms are appealing to researchers, as they can provide userindependent, robust, and automatic quantifications of various elements regarding neurite development and behavior (Frimat et al., 2010). Our team also recently developed AxoFluidic (available at www.tinyurl.com/AxoFluidic), a free, open-source program written in MATLAB designed to quantify axonal growth in microfluidic devices. Its algorithms quantify the axonal outgrowth along a longitudinal axis, taking into account the three distinct domains of the microfluidic device in the output profile. Furthermore, it calculates axonal length after a neurite skeletonization process, increasing the robustness of the outgrowth metrics to heterogeneous axonal calibers and changes in the intensity along an axon. AxoFluidic played a major role in demonstrating that a higher amount of DRG axons was able to reach the axonal compartment when collagen and laminin were used as substrates, whereas in alginate they reached longer distances (Neto et al., 2014). Axonal tracing algorithms have also been shown to take advantage of a microfluidic device upgraded to allow axons to grow in separate and parallel lines (Park et al., 2014a). Briefly, this algorithm can calculate axonal length by measuring the distance 


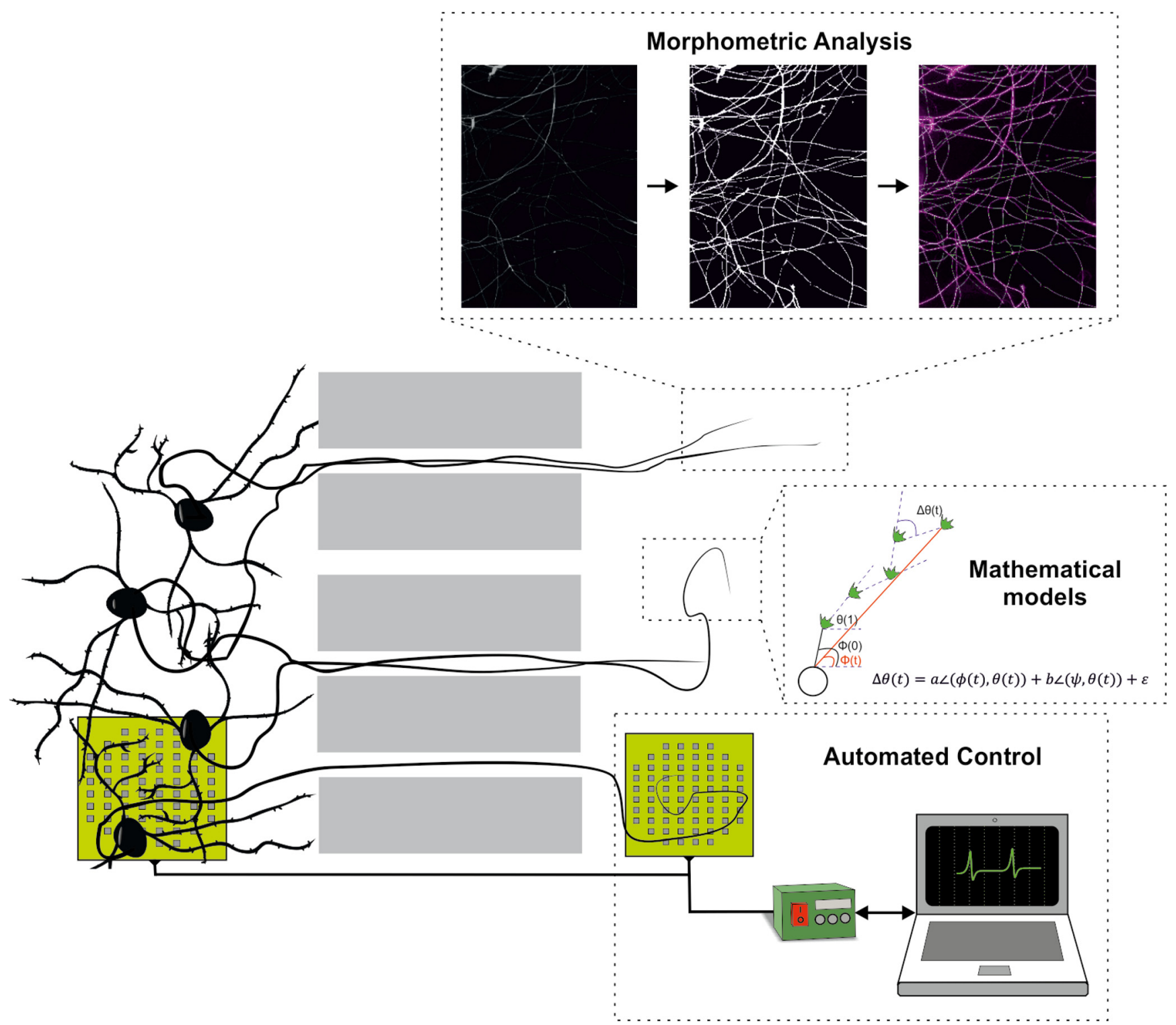

Figure 3. Schematic representation of neurons cultured in microfluidic platforms and then submitted to different computational analysis. Morphometric analysis: signal processing and data analysis, namely, specialized image processing algorithms of neuronal structures. Mathematical models: computer modeling, bridging experimental microfluidics data, and theoretical model. Automated control systems: manage sensors and actuators on advanced microfluidic platforms.

from the point where axons exit the microgrooves, to their endpoints, detected by scanning the image from the far end of the axonal compartment in a direction to the microgrooves.

Axonal degeneration has also been addressed by combining computational modeling and microfluidic technology. The AxonQuant algorithm (Li et al., 2014) allows a high-throughput, automatic, and quantitative analysis of axonal morphology in a manner independent of neuronal and axonal density. To develop this algorithm, researchers have redesigned a microfluidic chamber system to fit in a multiwell format to facilitate the application of the algorithm. The algorithm itself uses an artificial neural network trained with the features obtained from decomposed images of axonal bundles and can assess axonal health by determining the percentage of imaged axons that are continuous or segmented. This algorithm is able to analyze automatically large numbers of axonal bundles in a nonbiased manner and without manual selection of areas of interest. This algorithm allows a large-scale and high-throughput screening of genetic factors and pharmacological compounds that may alter axonal morphology, thus providing new insights into the mechanistic basis for axon degeneration (Li et al., 2014).

Aside from axonal behavior, other computational models have been described taking advantage of microfluidic technologies to, for example, improve the automatic quantification of the degree of myelination (Kerman et al., 2015). This method overcomes limitations of the methods available to the date, which includes the time-consuming manual counting and tracing of oligodendrocyte membranes, which often prevented the analysis of different conditions or the entire experimental area. Taking this into account, a fluorescence-based computer platform was developed on ImageJ that can identify and quantify myelin formation within a whole compartment, as well as detect changes in myelin formation. In this method, myelin quantification was based on the colocalization between neurons and oligodendrocytes, by counting its overlapping pixels, allowing the collection of several parameters, which enrich the analysis. 
The highly controlled environments offered by microfluidic technology have also allowed researchers to develop and parameterize mathematical models on complex cellular mechanisms. The ability to compartmentalize and accurately apply different experimental conditions has allowed researchers to isolate and describe individual components, or dynamics, of the mechanism of interest. This provides proper conditions to construct, parameterize, and validate biophysically detailed in silico models. A recent study focusing on axonal guidance clearly embodies the advantages of combining modeling with the controlled microfluidic environments (Nguyen et al., 2016). They presented a simple mathematical model explaining the highly stochastic axonal trajectories in a microfluidic-based in vitro system, resolving the mystery of the relative weak turning angle axons suffer when in the presence of a gradient and why axons often grow in straight lines. To achieve this, the authors have created an in silico model focused on the combined influence of axonal anchor points to the substrate, on the tendency to turn toward a gradient, and on the random movement noise. Moreover, to test this model quantitatively, a new microfluidic assay was developed for studying axonal response to gradients. By using time-lapse imaging, the behavior of axons from nerve fibers of rat brain was characterized over several hours of growth in both attractive and repulsive gradient conditions (Nguyen et al., 2016). The microfluidics platform combined with the mathematical analysis and modeling provided an effective approach to shed light on an important but previously unresolved problem. Noteworthy, computational modeling is also being used in the context of optimizing microfluidic platforms themselves and improving their control. In this research line, computational fluid dynamics, in particular, has been playing a crucial role in the characterization of microfluidic devices and their operating conditions (Santillo et al., 2007; Huang et al., 2010).

A third domain of computational methods associated with microfluidic-based platforms is also gaining momentum. As microfluidic platforms become more complex regarding sensing and actuation, it becomes necessary to have advanced control system capable of leveraging the platform's capabilities. Several standard microfluidic platforms are have now been upgraded and are able to automatically modulate distinct environmental settings (such as pressure, fluxes, temperatures, electrical stimulation, and concentrations) and record specific biological outputs (such as segregated molecules, gradients, electrophysiological signals). To fine (automated) control of these platforms is performed using specialized software and scripts in programming languages as LabVIEW or MATLAB (Erickson et al., 2005; Majumdar et al., 2011; Frank and Tay, 2015). To improve the control and readout of neuronal cultures, for example, the integration of microfluidic devices on microelectrode arrays has become extremely advantageous as it allows the stimulation and recording of neuronal electrical activity. When connected to a microfluidic platform, microelectrode arrays became even more attractive given the high control and precision over the cell microenvironment and its subcellular compartments (Gross et al., 2007; Biffi et al., 2012a). Recording of electric signals from growing axons in microfluidic devices, including propagation speed and direction of the action potentials, were described using specifically modified platforms (Dworak and Wheeler, 2009; Kanagasabapathi, 2009; Biffi et al., 2012a; Lewandowska et al., 2015). Still, and for more complex microenvironments such as neuronal networks, the challenge in the field is not only related to the miniaturization process, but also with the amplitude of the biological response. This results in an extremely challenging and arduous interface between the user and the miniaturized platform, ultimately requiring the development of accurate and highly elaborated software to decode the biological responses and specialized computational systems to perform real-time control of sensors (measuring devices) and actuators (action devices). Biffi et al. (2012b) have reported the development of a spatially and temporally controlled drug stimulation microfluidic device for neuronal networks. The device compartmentalization allows the recording of twin population subsets on the same chip when stimulated differently. For each compartment, the number of channels displaying spikes or bursts, burst duration, frequency, and network bursting rate could be analyzed in a single chip (Biffi et al., 2012b).

\section{Pharmacological manipulation and drug screening}

Microfluidic platforms are intended to reproduce complex microenvironments in simple devices, allowing researchers easy access to pharmacological manipulation, image acquisition, and data retrieval. Its complexity, however, has grown in such scale that researchers are now able to simulate different organs or whole biological systems in vitro that would be otherwise unmanageable at the macroscale level.

The organ-on-a-chip approach enables the development of novel in vitro disease models and arises as a promising alternative for animal testing (Ghaemmaghami et al., 2012; Esch et al., 2015). Aside from inexistent ethical dilemmas, it overcomes animal usage high cost, the often complexity of tissue and cell isolation, the need to use knock-out or transgenic animals, and the uncertain translation of animal results to humans. Furthermore, the possibility of using cells isolated directly from patients assures the biological relevance of studies, allowing a step forward on the comprehension of the disease. Taking this into account, a considerable effort has been made to the development of organ-ona-chip systems, including liver, intestinal, vascular, cardiac, lung, and brain platforms, to study not only physiological but also pathological processes, ranging from lung or intestinal cancer to diabetes and Alzheimer's disease (Leclerc et al., 2007; Nahmias et al., 2007; Bhise et al., 2014; Ebrahimkhani et al., 2014).

To date, there is an increased demand for an in vitro brain model that better mimics the in vivo microenvironment. Most of the in vitro studies of neurologic diseases lack essential features that characterize brain tissue. Among others, the complex brain network of fibers, responsible for the electrical transmission of information, as well as the presence of the surrounding interstitial liquid, responsible for nutrient delivery, waste clearance, and neural differentiation, are features difficult to introduce to an in vitro system.

Nevertheless, several platforms aiming to mimic brain function have already been described. Park et al. (2015) described a brain model in which the cell-cell communication and interstitial flow are preserved, allowing long-term in vitro observation without the need for peripheral devices. By using this platform, they showed that neurospheroid structures differentiated from neural progenitor cells, under a dynamic interstitial flow, were larger and presented a more robust neural network than the ones cultured under static conditions. This system can also be adapted to better understand neuronal function under pathologic conditions or to develop strategies for treatment of neurological diseases, such as Alzheimer's disease. With this device, researchers demonstrated a way to mimic normal and diseased brain on a single platform, by simultaneously culturing neurospheroid structures with and without amyloid- $\beta$, the peptide considered as the cause of Alzheimer's disease. This approach showed the neu- 

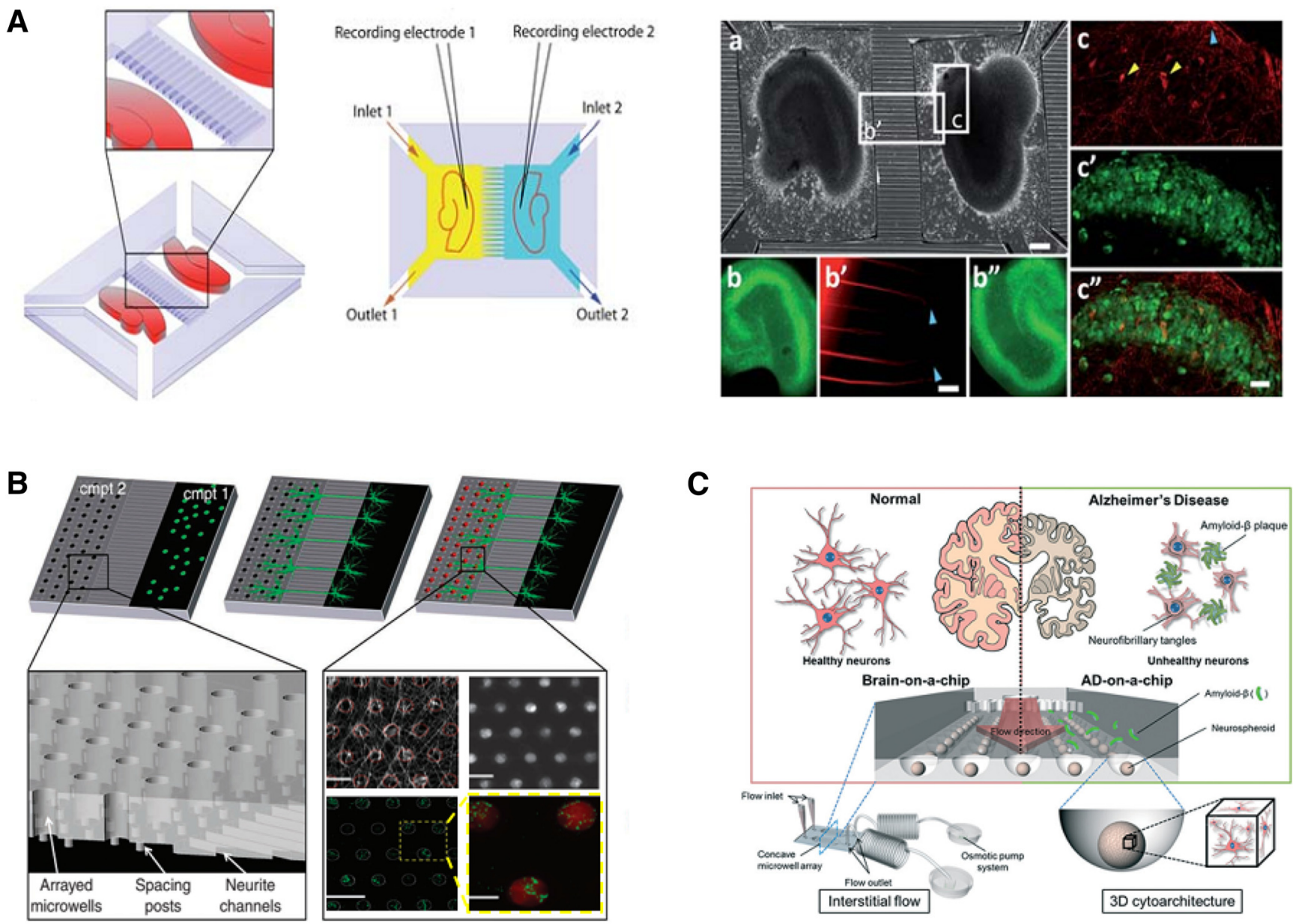

Figure 4. Microfluidic platforms to study neuronal networks and brain function in physiological and pathological conditions. A, Schematic representation of the hippocampus-hippocampus coculture in separated compartments. Axons in microchannels stained with Dil ( $\boldsymbol{b}^{\prime} ;$ red) and hippocampus slice counterstained with anti-NeuN ( $\boldsymbol{c}^{\prime} ;$ green) to reveal the position of the CA1 pyramidal layer. $\boldsymbol{B}$, Schematic of the synapse microarray technology (top and bottom left). Fluorescence image of neurites in the synapse microarray (white, bottom right) and synapsin (red). Adapted with permission from Macmillan Publishers (Shi et al., 2011). C, Schematic diagram of a 3 brain-on-a-chip showing the potential to simulate interstitial flow for physiological and pathological scenarios. A, C, Adapted with permission from The Royal Society of Chemistry (Park et al., 2014a, and Berdichevsky et al., 2010, respectively).

rotoxic effects of amyloid- $\beta$ underflow by analyzing key features that characterize Alzheimer's disease in vivo, such as cell viability, neural destruction, and synapse dysfunction (Park et al., 2015).

As we can easily understand from the study mentioned above, organ-on-chip technology can also be used to develop costeffective in vitro models for drug screening. These microfluidic platforms allow researchers to predict more reliably the efficacy, toxicity, and pharmacokinetics of drug compounds in humans, as well as to perform novel phenotypic screening assays. Berdichevsky et al. (2010) developed an in vitro brain platform capable of retaining the complex neural network connections and electrophysiological behavior while allowing pharmacological manipulation in distinct compartments. In this platform, cortex and hippocampal brain slices were cocultured in neighboring compartments, interconnected by microfluidic channels. Axons were allowed to form functional synaptic connections, mimicking the neural pathway between these two different brain regions. Furthermore, by culturing pairs of hippocampal slices, it was also possible to create a model of axonal sprouting in the CA1 hippocampal subregion, which could be further used to study epilepsy caused by excessive axonal sprouting in the CA1 hippocampal area. Finally, the fluidic isolation between the two compartments allows the pharmacological treatment of a single slice, enabling the study of the synaptic activity in the establish- ment, strengthening, and maintenance of neuronal circuits. This brain-on-chip platform clearly demonstrates the potential of microfluidic technologies to explore higher-order functions of complex tissues as well as a way to screen for new pharmacological tools to target neurological diseases.

Aside from the advance in vitro models of brain biology, microfluidic technology can also be applied in the development of high-throughput assays. Technologies for large-scale, genetic, and chemical synapse assays are necessary for fundamental research, and can lead to the identification of new drugs.

Over the years, synapse function has been the focus of many different therapeutic approaches, as many neurological disorders derive either from its abnormal functionality or affect directly its normal connectivity. Shi et al. (2011) developed a compartmentalized and highly sensitive synapse microarray device able to screen small synaptogenic molecules. Composed of two compartments spatially isolated from each other and connected by microchannels, researchers were able to induce synapse formation at specific sites, by introducing an array of microholes to the device. By using this platform, a decrease in the time needed to observe synapse formation was achieved, facilitating this way the execution of large-scale screens and acquisition of large amounts of data. Importantly, they were able to detect changes induced by chemicals in synapse function at very low concentrations. Up- 
grades in assay sensitivity and efficiency were key features for the detection of faint changes in synaptic function (Shi et al., 2011). Also, this platform could be easily upgraded to be applied to the study of other neuronal functions, such as neuronal development and cell-cell interactions (Fig. 4).

Microfluidic device high throughput technology arises as an incredibly attractive tool of excellence for pharmacological screening given its portability, price, and amount of reagents/ biofluid volume needed for drug testing. Drug screening is a complex, lengthy, and repetitive process that takes a significant deal of money. Daily, dozens of new potential therapeutic compounds require testing to predict its efficacy and toxicity. The combination of several analytical techniques in a microfluidic device, including electrical, enzymatic, fluorescent, and immunoassays, allows the simultaneous testing of multiple variables, such as cell viability, activity, phenotype, secreted factors, and metabolites (Gao et al., 2012).

In conclusion, microfluidic platforms have contributed tremendously to the evolution of the neurobiological in vitro platforms. Over the last years, an effort has been made to develop and continuously upgrade CMD to allow a faster translation to clinics. The development of accurate, sophisticated, and relevant tools to mimic both physiological and pathological conditions and the progress made on the interesting combination of computational models and microfluidic technology have been crucial to accurately translate biological responses to in vivo settings.

Microfluidics and microfabrication are highly versatile technologies, as perceived both by the wide range of studies available and the variety of designs found within the different research fields. Because of its features, studies exploring these technologies have grown exponentially and allowed different research areas to converge and work together toward common goals: engineers might use their background to improve the features of CMD to better control biological systems, whereas biologists work their way to miniaturize/simplify their hypothesis to fit these platforms. Other examples of success in merging different fields in a CMD technology context has already been achieved in areas, such as physics, electronics, mathematics, informatics, engineering, neurobiology, oncobiology, and stem cell research.

To date, neurobiology is the area that has advanced the most by taking advantage of the use of CMD. Because of the highly specialized neuronal architecture, efforts have been made to improve neuronal cultures and to establish new in vitro models to address different biological questions. Nevertheless, striking developments and discoveries are emerging in other fields alongside with neurobiology research, namely, in the regenerative medicine and biomaterials areas. These disciplines introduced interesting and complex upgrades to $\mathrm{CMD}$ with the incorporation of $3 \mathrm{D}$ microenvironments and structured cultures, for a controlled spatial relation between cells, or biomaterials for greater control over mechanical features (for review, see Bettinger and Borenstein, 2010; Domachuk et al., 2010; Kobel and Lutolf, 2011; Barata et al., 2016).

Even though many studies require complex systems, others require the simplest and minimalist environments, to reduce the number of incorporated variables. Single-cell approaches, for fundamental molecular studies, diverge from the development of the 3D organs-on-a-chip where complexity is the ultimate goal. Researchers must be mindful of this duality and weight, not only the biological hypothesis behind, but also the user-end community. It is crucial to remember that a user-friendly device will be easier to translate and implement across different laboratories, and it is imperative to keep balanced the commitment between the complexity of the in vitro system, the practicality of its use, and the cost production when considering an upscale to industry.

It is essential to be conscious that microfluidic systems still pose some challenges that need to be addressed. Constant upgrades, including the incorporation of bioanalytical stations for biological analysis, such as in situ detection of DNA/RNA/secreted proteins, will help to overcome some technical issues related to the low cell number, multiple cell types, and/or 2D/3D environment used. Moreover, the improvement on the readout of data obtained from these microfluidic systems using computational models will certainly support the achievement of faster and reliable outcomes. It is of the utmost importance that the development of new microfluidic devices must answer a scientific biological questions to guarantee results accuracy and faster translation to in vivo scenarios.

Undoubtedly, microfluidics have captured the complexity of human systems, and these devices are rapidly evolving, absorbing, and integrating cutting edge technology to be applied to the most challenging settings.

Overall, we believe that the merge of complementary fields of research will lead to new and relevant improvements of microfluidic technology, ultimately resulting in more accurate biological data.

\section{References}

Barata D, van Blitterswijk C, Habibovic P (2016) High-throughput screening approaches and combinatorial development of biomaterials using microfluidics. Acta Biomater 34:1-20. CrossRef Medline

Berdichevsky Y, Staley KJ, Yarmush ML (2010) Building and manipulating neural pathways with microfluidics. Lab Chip 10:999-1004. CrossRef Medline

Bettinger CJ, Borenstein JT (2010) Biomaterials-based microfluidics for engineered tissue constructs. Soft Matter 6:4999. CrossRef

Bhatia SN, Ingber DE (2014) Microfluidic organs-on-chips. Nat Biotechnol 32:760-772. CrossRef Medline

Bhise NS, Ribas J, Manoharan V, Zhang YS, Polini A, Massa S, Dokmeci MR, Khademhosseini A (2014) Organ-on-a-chip platforms for studying drug delivery systems. J Control Release 190:82-93. CrossRef Medline

Biffi E, Menegon A, Piraino F, Pedrocchi A, Fiore GB, Rasponi M (2012a) Validation of long-term primary neuronal cultures and network activity through the integration of reversibly bonded microbioreactors and MEA substrates. Biotechnol Bioeng 109:166-175. CrossRef Medline

Biffi E, Piraino F, Pedrocchi A, Fiore GB, Ferrigno G, Redaelli A, Menegon A, Rasponi M (2012b) A microfluidic platform for controlled biochemical stimulation of twin neuronal networks. Biomicrofluidics 6:241062410610. CrossRef Medline

Brunello CA, Jokinen V, Sakha P, Terazono H, Nomura F, Kaneko T, Lauri SE, Franssila S, Rivera C, Yasuda K, Huttunen HJ (2013) Microtechnologies to fuel neurobiological research with nanometer precision. J Nanobiotechnol 11:11. CrossRef Medline

Campenot RB (1977) Local control of neurite development by nerve growth factor. Proc Natl Acad Sci U S A 74:4516-4519. CrossRef Medline

Chenu C (2004) Role of innervation in the control of bone remodeling. J Musculoskelet Neuronal Interact 4:132-134. Medline

Chenu C, Marenzana M (2005) Sympathetic nervous system and bone remodeling. Joint Bone Spine 72:481-483. CrossRef Medline

Chokshi TV, Bazopoulou D, Chronis N (2010) An automated microfluidic platform for calcium imaging of chemosensory neurons in Caenorhabditis elegans. Lab Chip 10:2758-2763. CrossRef Medline

Chou HP, Spence C, Scherer A, Quake S (1999) A microfabricated device for sizing and sorting DNA molecules. Proc Natl Acad Sci U S A 96:11-13. CrossRef Medline

Coquinco A, Kojic L, Wen W, Wang YT, Jeon NL, Milnerwood AJ, Cynader M (2014) A microfluidic based in vitro model of synaptic competition. Mol Cell Neurosci 60:43-52. CrossRef Medline

Cosson S, Lutolf MP (2014a) Hydrogel microfluidics for the patterning of pluripotent stem cells. Sci Rep 4:4462. CrossRef Medline

Cosson S, Lutolf MP (2014b) Microfluidic patterning of protein gradients on biomimetic hydrogel substrates. Methods Cell Biol 121:91-102. CrossRef Medline

Cox LJ, Hengst U, Gurskaya NG, Lukyanov KA, Jaffrey SR (2008) Intra- 
axonal translation and retrograde trafficking of CREB promotes neuronal survival. Nat Cell Biol 10:149-159. CrossRef Medline

Croushore CA, Sweedler J V (2013) Microfluidic systems for studying neurotransmitters and neurotransmission. Lab Chip 13:1666-1676. CrossRef Medline

Deglincerti A, Liu Y, Colak D, Hengst U, Xu G, Jaffrey SR (2015) Coupled local translation and degradation regulate growth cone collapse. Nat Commun 6:6888. CrossRef Medline

Dinh ND, Chiang YY, Hardelauf H, Baumann J, Jackson E, Waide S, Sisnaiske J, Frimat JP, van Thriel C, Janasek D, Peyrin JM, West J (2013) Microfluidic construction of minimalistic neuronal co-cultures. Lab Chip 13: 1402-1412. CrossRef Medline

Domachuk P, Tsioris K, Omenetto FG, Kaplan DL (2010) Bio-microfluidics: biomaterials and biomimetic designs. Adv Mater 22:249-260. CrossRef Medline

Dupin I, Dahan M, Studer V (2013) Investigating axonal guidance with microdevice-based approaches. J Neurosci 33:17647-17655. CrossRef Medline

Dworak BJ, Wheeler BC (2009) Novel MEA platform with PDMS microtunnels enables the detection of action potential propagation from isolated axons in culture. Lab Chip 9:404-410. CrossRef Medline

Ebbesen CL, Bruus H (2012) Analysis of laser-induced heating in optical neuronal guidance. J Neurosci Methods 209:168-177. CrossRef Medline

Ebrahimkhani MR, Neiman JA, Raredon MS, Hughes DJ, Griffith LG (2014) Bioreactor technologies to support liver function in vitro. Adv Drug Deliv Rev 69:132-157. CrossRef Medline

Elefteriou F, Campbell P, Ma Y (2014) Control of bone remodeling by the peripheral sympathetic nervous system. Calcif Tissue Int 94:140-151. CrossRef Medline

Erickson D, Liu X, Venditti R, Li D, Krull UJ (2005) Electrokinetically based approach for single-nucleotide polymorphism discrimination using a microfluidic device. Anal Chem 77:4000 - 4007. CrossRef Medline

Esch EW, Bahinski A, Huh D (2015) Organs-on-chips at the frontiers of drug discovery. Nat Rev Drug Discov 14:248-260. CrossRef Medline

Folch A, Toner M (2000) Microengineering of cellular interactions. Annu Rev Biomed Eng 2:227-256. CrossRef Medline

Frank T, Tay S (2015) Automated co-culture system for spatiotemporal analysis of cell-to-cell communication. Lab Chip 15:2192-2200. CrossRef Medline

Franquinho F, Liz MA, Nunes AF, Neto E, Lamghari M, Sousa MM (2010) Neuropeptide $\mathrm{Y}$ and osteoblast differentiation-the balance between the neuro-osteogenic network and local control. FEBS J 277:3664-3674. CrossRef Medline

Frimat JP, Sisnaiske J, Subbiah S, Menne H, Godoy P, Lampen P, Leist M, Franzke J, Hengstler JG, van Thriel C, West J (2010) The network formation assay: a spatially standardized neurite outgrowth analytical display for neurotoxicity screening. Lab Chip 10:701-709. CrossRef Medline

Fukuda T, Takeda S, Xu R, Ochi H, Sunamura S, Sato T, Shibata S, Yoshida Y, Gu Z, Kimura A, Ma C, Xu C, Bando W, Fujita K, Shinomiya K, Hirai T, Asou Y, Enomoto M, Okano H, et al. (2013) Sema3A regulates bone-mass accrual through sensory innervations. Nature 497:490-493. CrossRef Medline

Gao D, Liu HX, Jiang YY, et al. (2012) Recent developments in microfluidic devices for in vitro cell culture for cell-biology research. Trends Anal Chem 35:150-164. CrossRef

Gao Y, Majumdar D, Jovanovic B, Shaifer C, Lin PC, Zijlstra A, Webb DJ, Li D (2011) A versatile valve-enabled microfluidic cell co-culture platform and demonstration of its applications to neurobiology and cancer biology. Biomed Microdevices 13:539-548. CrossRef Medline

Ghaemmaghami AM, Hancock MJ, Harrington H, Kaji H, Khademhosseini A (2012) Biomimetic tissues on a chip for drug discovery. Drug Discov Today 17:173-181. CrossRef Medline

Gross PG, Kartalov EP, Scherer A, Weiner LP (2007) Applications of microfluidics for neuronal studies. J Neurol Sci 252:135-143. CrossRef Medline

Gumy LF, Yeo GS, Tung YC, Zivraj KH, Willis D, Coppola G, Lam BY, Twiss JL, Holt CE, Fawcett JW (2011) Transcriptome analysis of embryonic and adult sensory axons reveals changes in mRNA repertoire localization. RNA 17:85-98. CrossRef Medline

Hasan A, Paul A, Vrana NE, Zhao X, Memic A, Hwang YS, Dokmeci MR, Khademhosseini A (2014) Microfluidic techniques for development of $3 \mathrm{D}$ vascularized tissue. Biomaterials 35:7308-7325. CrossRef Medline

Huang M, Fan S, Xing W, Liu C (2010) Microfluidic cell culture system studies and computational fluid dynamics. Math Comput Model 52: 2036-2042. CrossRef

Hyun Sung P, Su L, McDonald J, et al. (2013) Neuromuscular junction in a microfluidic device. In: 2013 35th Annual International Conference of the IEEE Engineering in Medicine and Biology Society, IEEE, pp 2833-2835.

Kanagasabapathi T (2009) Dual-compartment microfluidic device for neuronal co-cultures. Proc IEEE Eng Med Biol Soc 1655-1658.

Kerman BE, Kim HJ, Padmanabhan K, Mei A, Georges S, Joens MS, Fitzpatrick JA, Jappelli R, Chandross KJ, August P, Gage FH (2015) In vitro myelin formation using embryonic stem cells. Development 142:22132225. CrossRef Medline

Kimpinski K, Campenot RB, Mearow K (1997) Effects of the neurotrophins nerve growth factor, neurotrophin-3, and brain-derived neurotrophic factor (BDNF) on neurite growth from adult sensory neurons in compartmented cultures. J Neurobiol 33:395-410. CrossRef Medline

Kobel S, Lutolf MP (2011) Biomaterials meet microfluidics: building the next generation of artificial niches. Curr Opin Biotechnol 22:690-697. CrossRef Medline

Kothapalli CR, van Veen E, de Valence S, Chung S, Zervantonakis IK, Gertler FB, Kamm RD (2011) A high-throughput microfluidic assay to study neurite response to growth factor gradients. Lab Chip 11:497-507. CrossRef Medline

Kung F, Wang J, Perez-Castillejos R, Townes-Anderson E (2015) Position along the nasal/temporal plane affects synaptic development by adult photoreceptors, revealed by micropatterning. Integr Biol (Camb) 7:313323. CrossRef Medline

Lai N, Sims JK, Jeon NL, Lee K (2012) Adipocyte induction of preadipocyte differentiation in a gradient chamber. Tissue Eng Part C Methods 18:958 967. CrossRef Medline

Leclerc E, Baudoin R, Corlu A, Griscom L, Luc Duval J, Legallais C (2007) Selective control of liver and kidney cells migration during organotypic cocultures inside fibronectin-coated rectangular silicone microchannels. Biomaterials 28:1820-1829. CrossRef Medline

Lee Y, Kim HJ, Park CK, Kim WS, Lee ZH, Kim HH (2012) Novel extraneural role of neurite outgrowth inhibitor A: modulation of osteoclastogenesis via positive feedback regulation of nuclear factor of activated $\mathrm{T}$ cell cytoplasmic 1. J Bone Miner Res 27:1043-1054. CrossRef Medline

Lei Y, Li J, Wang N, Yang X, Hamada Y, Li Q, Zheng W, Jiang X (2016) An on-chip model for investigating the interaction between neurons and cancer cells. Integr Biol (Camb) 8:359-367. CrossRef Medline

Lewandowska MK, Bakkum DJ, Rompani SB, Hierlemann A (2015) Recording large extracellular spikes in microchannels along many axonal sites from individual neurons. PLoS One 10:e0118514. CrossRef Medline

Li L, Ren L, Liu W, Wang JC, Wang Y, Tu Q, Xu J, Liu R, Zhang Y, Yuan MS, Li T, Wang J (2012) Spatiotemporally controlled and multifactor involved assay of neuronal compartment regeneration after chemical injury in an integrated microfluidics. Anal Chem 84:6444-6453. CrossRef Medline

Li YT, Zhang SH, Wang XY, Zhang XW, Oleinick AI, Svir I, Amatore C, Huang WH (2015) Real-time monitoring of discrete synaptic release events and excitatory potentials within self-reconstructed neuromuscular junctions. Angew Chem Int Ed Eng; 54:9313-9318. CrossRef Medline

Li Y, Yang M, Huang Z, Chen X, Maloney MT, Zhu L, Liu J, Yang Y, Du S, Jiang X, Wu JY (2014) AxonQuant: a microfluidic chamber culturecoupled algorithm that allows high-throughput quantification of axonal damage. Neurosignals 22:14-29. CrossRef Medline

Liu Z, Liu H, Li Z (2008) Formation of neuromuscular junctions and synthesis of sensory neuropeptides in the co-cultures of dorsal root ganglion and cardiac myocytes. Cell Mol Neurobiol 28:939-947. CrossRef Medline

Lu X, Kim-Han JS, O’Malley KL, Sakiyama-Elbert SE (2012) A microdevice platform for visualizing mitochondrial transport in aligned dopaminergic axons. J Neurosci Methods 209:35-39. CrossRef Medline

Mahadik BP, Wheeler TD, Skertich LJ, Kenis PJ, Harley BA (2014) Microfluidic generation of gradient hydrogels to modulate hematopoietic stem cell culture environment. Adv Healthc Mater 3:449-458. CrossRef Medline

Majumdar D, Gao Y, Li D, Webb DJ (2011) Co-culture of neurons and glia in a novel microfluidic platform. J Neurosci Methods 196:38-44. CrossRef Medline

McDonald JC, Duffy DC, Anderson JR, Chiu DT, Wu H, Schueller OJ, Whitesides GM (2000) Fabrication of microfluidic systems in poly (dimethylsiloxane). Electrophoresis 21:27-40. CrossRef Medline 
McUsic AC, Lamba DA, Reh TA (2012) Guiding the morphogenesis of dissociated newborn mouse retinal cells and hES cell-derived retinal cells by soft lithography-patterned microchannel PLGA scaffolds. Biomaterials 33:1396-1405. CrossRef Medline

Md Yunus NA (2013) Microfluidic devices fabrication for bioelectrokinetic system applications. In: Electrochemistry (Khalid M, ed). Croatia: InTech.

Meyvantsson I, Beebe DJ (2008) Cell culture models in microfluidic systems. Annu Rev Anal Chem (Palo Alto Calif) 1:423-449. CrossRef Medline

Millet LJ, Gillette MU (2012) Over a century of neuron culture: from the hanging drop to microfluidic devices. Yale J Biol Med 85:501-521. Medline

Moreno EL, Hachi S, Hemmer K, Trietsch SJ, Baumuratov AS, Hankemeier T, Vulto P, Schwamborn JC, Fleming RM (2015) Differentiation of neuroepithelial stem cells into functional dopaminergic neurons in 3D microfluidic cell culture. Lab Chip 15:2419-2428. CrossRef Medline

Nahmias Y, Berthiaume F, Yarmush ML (2007) Integration of technologies for hepatic tissue engineering. Adv Biochem Eng Biotechnol 103:309329. Medline

Neto E, Alves CJ, Sousa DM, Alencastre IS, Lourenço AH, Leitão L, Ryu HR, Jeon NL, Fernandes R, Aguiar P, Almeida RD, Lamghari M (2014) Sensory neurons and osteoblasts: close partners in a microfluidic platform. Integr Biol (Camb) 6:586. CrossRef Medline

Nguyen H, Dayan P, Pujic Z, Cooper-White J, Goodhill GJ (2016) A mathematical model explains saturating axon guidance responses to molecular gradients. Elife 5:1-25. CrossRef Medline

Oiwa K, Shimba K, Numata T, Takeuchi A, Kotani K, Jimbo Y (2016) A device for co-culturing autonomic neurons and cardiomyocytes using micro-fabrication techniques. Integr Biol (Camb) 8:341-348. CrossRef Medline

Pagella P, Neto E, Jiménez-Rojo L, Lamghari M, Mitsiadis TA (2014) Microfluidics co-culture systems for studying tooth innervation. Front Physiol 5:326. CrossRef Medline

Pagella P, Neto E, Lamghari M, Mitsiadis TA (2015) Investigation of orofacial stem cells niches and their innervation through microfluidic devices. Eur Cells Mater 29:213-223. CrossRef Medline

Park HS, Liu S, McDonald J, Thakor N, Yang IH (2013a) Neuromuscular junction in a microfluidic device. Conf Proc IEEE Eng Med Biol Soc 2013:2833-2835. CrossRef Medline

Park JW, Vahidi B, Taylor AM, Rhee SW, Jeon NL (2006) Microfluidic culture platform for neuroscience research. Nat Protoc 1:2128-2136. CrossRef Medline

Park JW, Kim HJ, Kang MW, Jeon NL (2013b) Advances in microfluidicsbased experimental methods for neuroscience research. Lab Chip 13: 509-521. CrossRef Medline

Park J, Koito H, Li J, Han A (2009) Microfluidic compartmentalized coculture platform for CNS axon myelination research. Biomed Microdevices 11:1145-1153. CrossRef Medline

Park J, Koito H, Li J, Han A (2012) Multi-compartment neuron-glia coculture platform for localized CNS axon-glia interaction study. Lab Chip 12:3296-3304. CrossRef Medline

Park J, Kim S, Park SI, Choe Y, Li J, Han A (2014a) A microchip for quantitative analysis of CNS axon growth under localized biomolecular treatments. J Neurosci Methods 221:166-174. CrossRef Medline

Park J, Lee BK, Jeong GS, Hyun JK, Lee CJ, Lee SH (2015) Threedimensional brain-on-a-chip with an interstitial level of flow and its application as an in vitro model of Alzheimer's disease. Lab Chip 15: 141-150. CrossRef Medline

Prieto JL, Lu J, Nourse JL, Flanagan LA, Lee AP (2012) Frequency discretization in dielectrophoretic assisted cell sorting arrays to isolate neural cells. Lab Chip 12:2182-2189. CrossRef Medline

Rasponi M, Piraino F, Sadr N, et al. (2011) Reliable magnetic reversible assembly of complex microfluidic devices: fabrication, characterization, and biological validation. Microfluid Nanofluidics 10:1097-1107. CrossRef

Rhee SW, Taylor AM, Tu CH, Cribbs DH, Cotman CW, Jeon NL (2005) Patterned cell culture inside microfluidic devices. Lab Chip 5:102-107. CrossRef Medline

Sackmann EK, Fulton AL, Beebe DJ (2014) The present and future role of microfluidics in biomedical research. Nature 507:181-189. CrossRef Medline
Santillo MF, Arcibal IG, Ewing AG (2007) Flow characterization of a microfluidic device to selectively and reliably apply reagents to a cellular network. Lab Chip 7:1212-1215. CrossRef Medline

Shi P, Nedelec S, Wichterle H, Kam LC (2010) Combined microfluidics/ protein patterning platform for pharmacological interrogation of axon pathfinding. Lab Chip 10:1005-1010. CrossRef Medline

Shi P, Scott MA, Ghosh B, Wan D, Wissner-Gross Z, Mazitschek R, Haggarty SJ, Yanik MF (2011) Synapse microarray identification of small molecules that enhance synaptogenesis. Nat Commun 2:510. CrossRef Medline

Southam KA, King AE, Blizzard CA, McCormack GH, Dickson TC (2013) Microfluidic primary culture model of the lower motor neuron-neuromuscular junction circuit. J Neurosci Methods 218:164-169. CrossRef Medline

Takeuchi A, Nakafutami S, Tani H, Mori M, Takayama Y, Moriguchi H, Kotani K, Miwa K, Lee JK, Noshiro M, Jimbo Y (2011) Device for coculture of sympathetic neurons and cardiomyocytes using microfabrication. Lab Chip 11:2268-2275. CrossRef Medline

Takeuchi A, Shimba K, Mori M, Takayama Y, Moriguchi H, Kotani K, Lee JK, Noshiro M, Jimbo Y (2012) Sympathetic neurons modulate the beat rate of pluripotent cell-derived cardiomyocytes in vitro. Integr Biol (Camb) 4:1532-1539. CrossRef Medline

Taylor AM, Rhee SW, Tu CH, Cribbs DH, Cotman CW, Jeon NL (2003) Microfluidic multicompartment device for neuroscience research. Langmuir 19:1551-1556. CrossRef Medline

Taylor AM, Blurton-Jones M, Rhee SW, Cribbs DH, Cotman CW, Jeon NL (2005) A microfluidic culture platform for CNS axonal injury, regeneration and transport. Nat Methods 2:599-605. CrossRef Medline

Taylor AM, Berchtold NC, Perreau VM, Tu CH, Li Jeon N, Cotman CW (2009) Axonal mRNA in uninjured and regenerating cortical mammalian axons. J Neurosci 29:4697-4707. CrossRef Medline

Taylor AM, Menon S, Gupton SL (2015) Passive microfluidic chamber for long-term imaging of axon guidance in response to soluble gradients. Lab Chip 15:2781-2789. CrossRef Medline

Tehranirokh M, Kouzani AZ, Francis PS, Kanwar JR (2013) Microfluidic devices for cell cultivation and proliferation. Biomicrofluidics 7:51502. CrossRef Medline

Théry M (2010) Micropatterning as a tool to decipher cell morphogenesis and functions. J Cell Sci 123:4201-4213. CrossRef Medline

Unger MA, Chou HP, Thorsen T, Scherer A, Quake SR (2000) Monolithic microfabricated valves and pumps by multilayer soft lithography. Science 288:113-116. CrossRef Medline

Uzel SG, Pavesi A, Kamm RD (2014) Microfabrication and microfluidics for muscle tissue models. Prog Biophys Mol Biol 115:279-293. CrossRef Medline

Vukasinovic J, Cullen DK, LaPlaca MC, Glezer A (2009) A microperfused incubator for tissue mimetic 3D cultures. Biomed Microdevices 11:11551165. CrossRef Medline

Whitesides GM (2006) The origins and the future of microfluidics. Nature 442:368-373. CrossRef Medline

Wu J, Wu X, Lin F (2013) Recent developments in microfluidics-based chemotaxis studies. Lab Chip 13:2484-2499. CrossRef Medline

Wu KY, Hengst U, Cox LJ, Macosko EZ, Jeromin A, Urquhart ER, Jaffrey SR (2005) Local translation of RhoA regulates growth cone collapse. Nature 436:1020-1024. CrossRef Medline

Xiong B, Ren K, Shu Y, Chen Y, Shen B, Wu H (2014) Recent developments in microfluidics for cell studies. Adv Mater 26:5525-5532. CrossRef Medline

Xu R (2014) Semaphorin 3A a new player in bone remodeling. Cell Adhes Migr 8:5-10. CrossRef Medline

Yang IH, Gary D, Malone M, Dria S, Houdayer T, Belegu V, McDonald JW, Thakor N (2012) Axon myelination and electrical stimulation in a microfluidic, compartmentalized cell culture platform. Neuromolecular Med 14:112-118. CrossRef Medline

Young EW, Beebe DJ (2010) Fundamentals of microfluidic cell culture in controlled microenvironments. Chem Soc Rev 39:1036-1048. CrossRef Medline

Zahavi EE, Ionescu A, Gluska S, Gradus T, Ben-Yaakov K, Perlson E (2015) A compartmentalized microfluidic neuromuscular co-culture system reveals spatial aspects of GDNF functions. J Cell Sci 128:1241-1252. CrossRef Medline

Zhang C, van Noort D (2011) Cells in microfluidics. Top Curr Chem 304: 295-321. CrossRef Medline 